\title{
İKİ KÖPEKTE FEMURUN MEDİAL KONDİLUS KIRIĞININ (SALTER-HARRİS TİP III) OSTEOSENTEZ İLE SAĞALTIMI
}

\begin{abstract}
$\ddot{U}$ mit $K A Y A^{I}$
Arkun CANDAŞ ${ }^{2}$

Operative management of medial condylar fracture of femur (Salter-Harris type III) in two dogs

Summary: Two dogs which are brought at Ankara University Veterinary Faculty, Section of Orthopedics and Traumatology, have got fractures of medial condylus of femur (Salter-Harris typelII) which are revealed by clinical and radiological evaluations.

In the operation management, the fixations and stabilizations achieved by transcondylar multiple Kirshner wires in firsth dog and single cancellous screw in second dog. The result is good in firsth dog but, the second dog has got lamaness and mild degenerative joint disease due to delayed treatment attempt.
\end{abstract}

Key words: Condylar fracture, dog, femur, Salter-Harris

Özet: Ankara Üniversitesi Veteriner Fakültesi Ortopedi ve Travmatoloji Bilim Dalı Kliniğine getirilen 2 köpekte yapllan klinik ve radyolojik muayeneler sonucunda distal femur medial kondilus (Salter-Harris tip III) kırı̆̆ belirlendi.

Olguların operatif să̆altımında, birinci köpekte kırı̆̆ın fikzasyonu multiple Kisrchner pinleri, diğer köpekte ise tek spongioz vida ile sağaltım sağlandı. Birinci köpekte istenilen săgaltım sonuçlarına ulaşılırken, ikinci köpekte geciken să̆altım girişimi nedeniyle dejeneratif artritis ve topallık gelisimi izlendi.

Anahtar kelimeler: Femur, kondilus kırı̆̆ı, köpek, Salter-Harris

\section{Giriş}

Femur distali epifiz, metafiz ve gelişimini tamamlamamış hayvanlarda gözlenen fizis bölgelerinden oluşur. Fizis bölgesi kraniokaudal ve mediolateral perspektifte "W" şeklini alarak, metafizden 4 adet çıkıntı ve epifizden de 4 adet buna uygun girinti oluşturur (5).

Fizis bölgesi kınkları, genellikle 3-11 aylık gelişimini tamamlamamış hayvanlarda, özel- likle de 5-8 aylik olanlarda daha sik görülmektedir(1,3,4,5). Köpeklerde femurun distalinde en sık oluşan kırıklar "Salter-Harris (SH) tip II" kınklandır. Kedilerde ise S-H tip I k1rıkları daha çok gözlenmektedir $(3,5,6)$. SalterHarris tip III, IV ve interkondiler kırıklar ise her iki türde ve yaş grubunda az oranda, fakat olgun hayvanlarda daha fazla görülür $(1,3,5)$ Tek taraflı femur kondilus kınklaninda kollatcral ve cruciate ligamentlerin kırık kondülle 
bağlantıları fragmanların deplasmanını önlediğinden iki yönlï, özellikle de mediolateral pozisyonda alınan radyografilerle kesin taniya ulaşılır. Basit interkondiler kırıklar genellikle medial kondilusu içerir $(2,3,4,5)$. Carmichael ve ark (2), tek taraflı femur kondilus kurıkları ile ilgili 9 köpeğin değerlendirildiği bir çalışmada, 8 köpekte medial kondilus kırı̆ı gözlemlemişlerdir.

Tek taraflı femur kondilus kırıklanını sağaltımında, transkondiler multiple Kirschner (K) tellcri veya lag vida uygulamalan ya da her iki yöntemin kombinasyonları kullanılır $(1,2,3,5,6)$. Multiple $\mathrm{K}$ telleri uygulaması ile kuiçük yapılı köpek ırklan ve kedilerde ycterli fikzasyona ulaşılırken, orta ya da iri yapılı köpek ırklarında kortikal veya spongioz kemik vidaları uygulanabilir $(4,5)$. Vida ve pinlerin uygulamasında kırık hattına dik pozisyonda olmasına; vida başının da eklem hareketlerini engellememesine dikkat edilmelidir. Rotasyonel stabiliteyi önlemek için tek vida uygulamaları ile beraber paralel ikinci vida ya da K teli uygulaması önerilir (6).

Bu kırıklarda eklem yapısının restorasyonu ve ligamentöz stabilitesi için rijid fikzasyon ve anatomik redüksiyon çok önemlidir. Yeterli rediiksiyon ve fikzasyona ulaşılamadığında dejencratif eklem hastalığının gelişimi gözlenebilir $(1,4,5)$. Kırlk hattının femur trochleasına ulaşmadığı ve dejeneratif eklem hastalığının gelişmediği olgularda ise, kondiler kırıkların sağaltımında olumlu sonuçların alındığı bildirilmiştir (3). Bu çalışmada, distal femur kırık tipleri içinde oldukça az görülen femurun medial kondilus kınğı bclirlenen iki köpeğin klinik ve radyolojik muayenelcrle değerlendirilmesi ve sağaltım sonuçlarının aktarılması amaçlanmıştır.

\section{Materyal ve Metot}

AÜ Veteriner Fakültesi Ortopedi ve Travmatoloji Bilim Dalı Kliniğine getirilen 1 yaşlı, erkek, Alman çoban köpcği mclezi ile (protokol defteri kayıt no:936/1996) ve 8 yaşli, erkek, Alman çoban köpeği (protokol defteri kayıt no: 1754/1999) çalışma materyalini oluşturdu.
Birinci köpeğin sahibinden alınan anamnezinde, bir gün önce trafik kazası geçirdiği ve sağ arka ekstremitesini kullanamadığı, ikinci köpcğin anamnezinde ise, 10 gün önce trafik kazası geçirdiği ve sol arka ekstremitesini kullanamadığı bildirilmiştir. Klinik muayene sonrasında ilgili bölgelerin yapılan iki yönlü radyografik muayenesinde, her iki köpekte de tek taraflı femurun medial kondilus kırığ (S-H tip III) belirlenmiştir.

Operatif sağaltım için olgunun genel anestezisi, xylazine hidrochlorid (Rompun $23.32 \mathrm{mg} / \mathrm{kg}$, Bayer) premedikasyonu sonrasında uygulanan ketamine hidroklorid (Ketalar, 50mg/ml, Parkc-Davis) ile sağlandı. Bölgenin operasyon için hazırlanması sonrasında ilgili ekstremite altta kalacak ve üstteki ckstremite kaudalc yönlendirilecek şekilde köpek lateral konumda operasyon masasına tespit edildi.

Bölgeye bilinen yöntemlerle ulaşıldıktan sonra fikzasyon iki $\mathrm{K}$ telinin medial kondilustan lateral kondilusa yönlendirilmesi ile sağlanmıştır. Ikinci olguda ise fikzasyon materyali olarak tek spongioz vida kullanılmıştır (Şekil 1,2,3,4).

Operasyon bölgesi kapatıldıktan sonra, ekstrcmite 10 gün PVC destckli bandaj ile korundu. Postoperatif lokal ve 5 gün suireli parentcral antibiyotik (Linco-spektin,50mg linkomisin hidroklorür $+100 \mathrm{mg}$ spektinomisin sülfat tetrahidrat/ml, Eczacıbaşı) uygulandı.

\section{Bulgular}

Postopcratif olarak uygulanan PVC destekli bandajın uzaklaştırılması sırasında deri dikişleri alındı. Diz ckleminde oluşabilecek eklem sertliğine karşı eklemin erken hareket etmesi için 3 hafta kontrollü hareket ve tasmalı yürüyüş uygulandı. Dördüncui hafta sonundaki kontrollerde birinci olguda fonksiyonel tam iyileşme sağlanırken, geciken sağalım girişimi nedeniyle tam redüksiyonun sağlanamadığı 2 . olguda dejeneratif artril gelişimi ve uzun süren topallık gözlendi. 


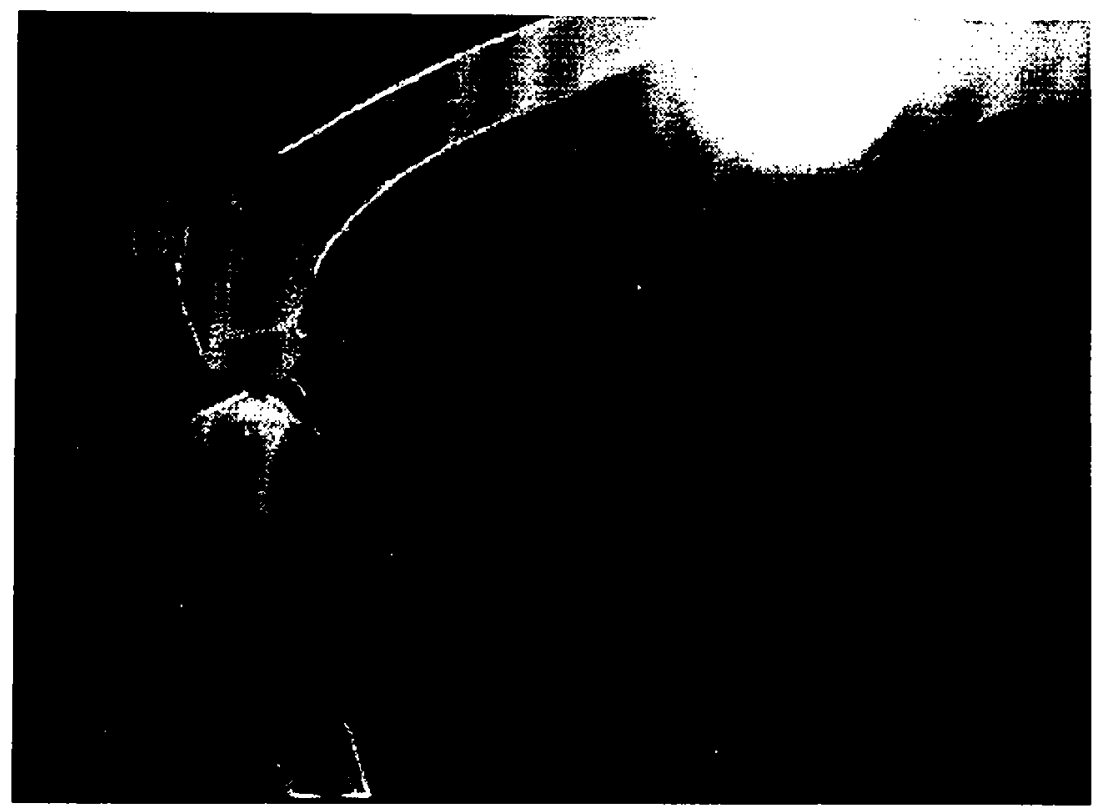

Şckil 1. Birinci köpeğin preoperaltil radyografik gärianiimii.

Figure 1. Preoperative radiographic vicw of litst dog.

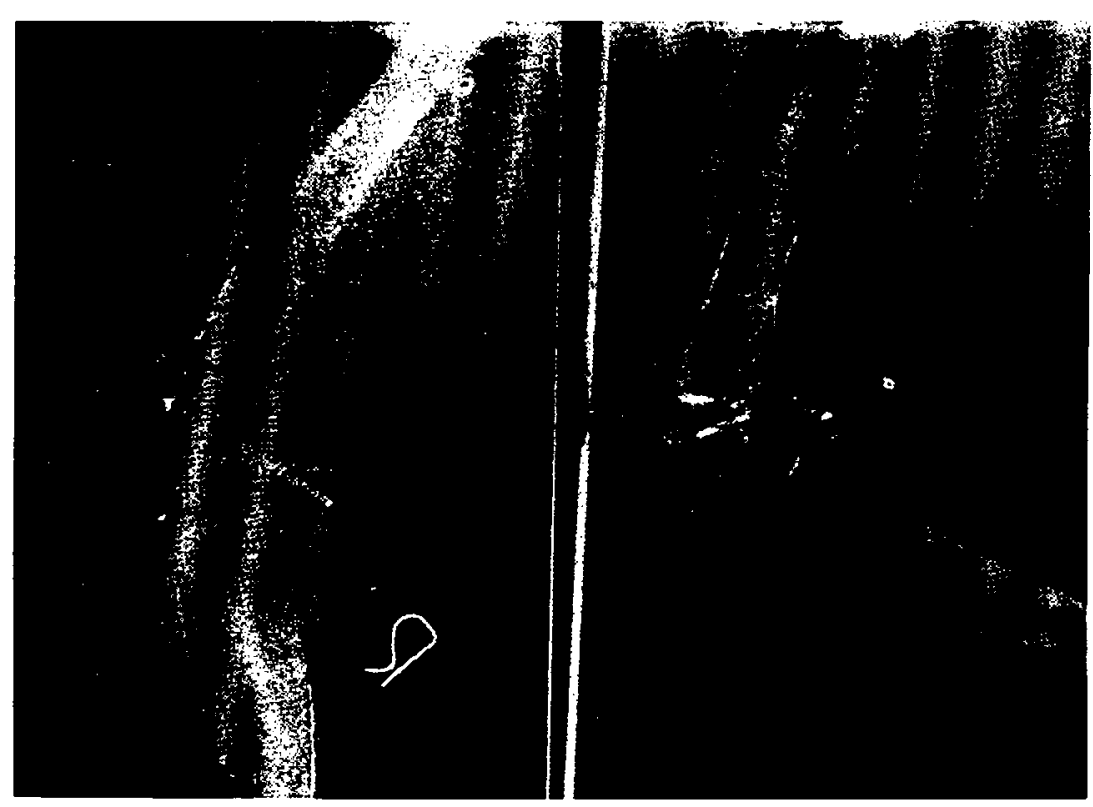

Şekil 2. Birinci köpeğin postoperatif radyogratik goruniumu.

Figure 2. Postoperative radiographic view of first dog.

\section{Tartışma ve Sonuç}

Literatür verilerce $(1,3,5)$, fizis bölgesi k1rıklannın, genellikle 3-11 aylık gelişimini tamamlamamış hayvanlarda, özclliklede 5-8 aylık olanlarda daha fazla görüldügü bildirilmektedir.
Salter-Harris tip III-IV ve interkondiler k1rıkların ise, hem gelişme döneminde olan hem de gelişimini tamamlamış hayvanlarda az oranda görüldügü, fakat gelişimini tamamlamış hayvanlarda daha sıklıkla gözlendiği bildirilmiştir. $\mathrm{Bu}$ çalışmada gözlenen femur medial kondilus 


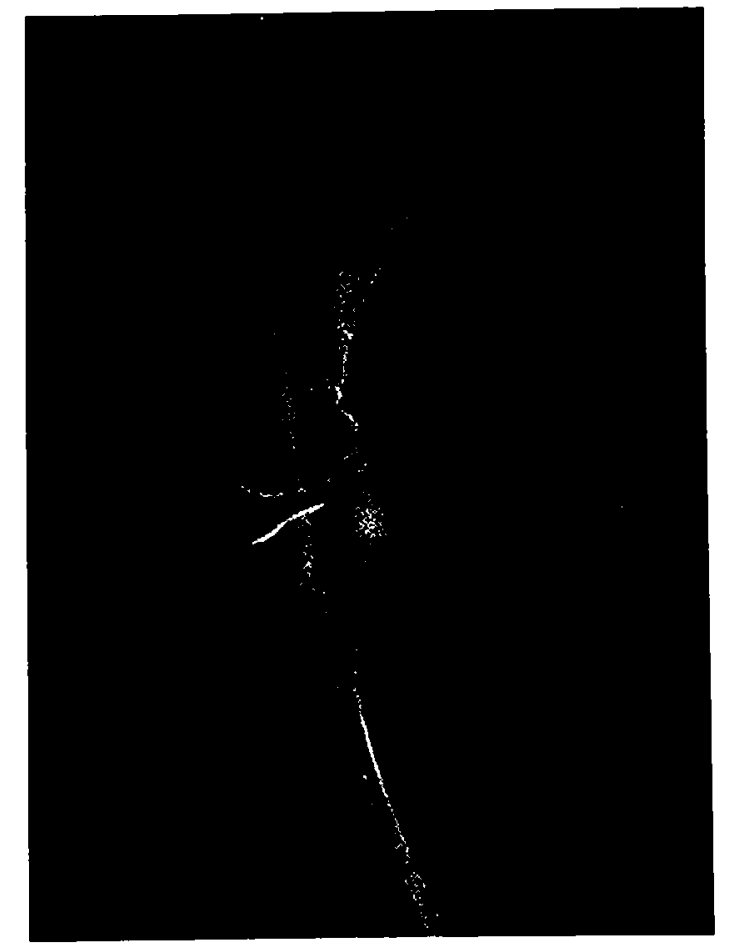

Şekil 3. Ikınci köpeģin preoperatif radyografik görünümii.

Figure 3. Prcoperative radiographic view of sccond dog.

kırıkları ise, gelişimini tamamlamış hayvanlarda ve uzun bir zaman dilimi içinde sadece iki köpekte görülmesi ile litaratür verilerle uyum sağlamaktadır. Interkondiler kırıkların genelikle medial kondilusu içerdiği bildirilmektedir $(2,3,4,5)$. Carmichael ve ark (2), tek taraflı femur kondilus kırıklan ile ilgili 9 köpeklik bir değcrlendirmede 8 köpekte medial kondilus kırığı gözlemlediklerini bildirmişlerdir. Bu çalışmadaki köpeklerde de femurun medial kondilus kırığı gözlenmiştir.

$\mathrm{Bu}$ kırikların tam redüksiyonunun ve internal fikzasyonunun eklemin ligamentöz stabilitesi için çok önemli olduğu, istenilen fikzasyonun ve stabilizasyonun yapılamaması durumunda dejencratif cklem hastalığı gelişimine neden olacă̆ı bildirilmektedir $(1,4,5)$. Ayrıca, dejeneratif eklem hastalığının gelişmediği olgularda kondiler kırıkların sağaltım sonuçlarının çok iyi olduğuna değinilmektedir (3).

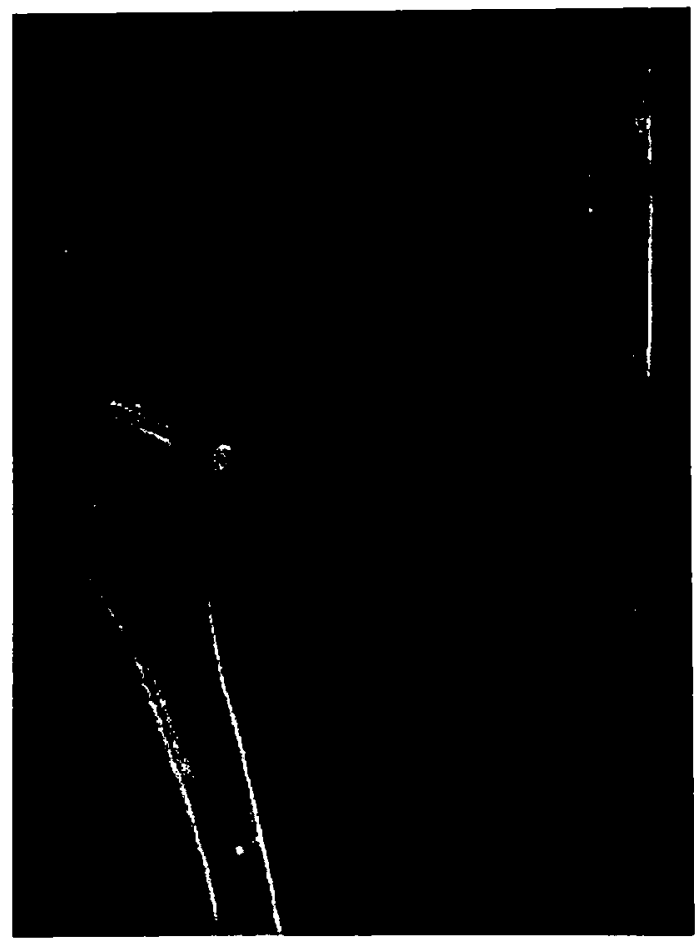

Şckil 4. Ikinci köpeğin postoperatif radyogratik görünümü.

Figure 4. Postoperative radiographic view of second dog.

Bu çalışmada, birinci köpek hemen olay sonrası getirilmesi nedeniyle arzulanan rcdüksiyon ve fikzasyona kolaylıkla ulaşılmıştır. Ikinci köpek ise, kronik dönemde ve intraartiküler dejeneratif değişiklikler başladığında getirilmiştir. $\mathrm{Bu}$ olguda oluşan fibrozis nedeniyle istenilen rediksiyon sağlanamamı̧ fakat köpek uzun dönemde fonksiyonel iyileşme gözlenmiştir.

Distal femur medial kondilus kınklannın, eklem içi kırık olması nedeniyle en kısa sürede ve tam anatomik reduiksiyonda fikzasyonunun sağlanmasının sağaltımın başarısı açısından çok önemli olduğu kanısına varılmıştır.

\section{Kaynaklar}

1. Brinker WO, Hohn RB, Prieur WD (1984) Manual of Internal Fixation in Small Animals. SpringerVerlag. Berlin. 165-175.

2. Carmicheal S, Wheeler SO, Vaughan I.C (1990) Single condylar fractures of the distal femur in the dog. Eur Companion Anim, 1, 8-12. 
3. Denny HR (1993) A Guide to Canine and Feline Orthopaedic:s Surgery. Third Edition. Blackwell Science. Oxford, 349-351.

4. Gilmore, DR (1990) Internal Fixation of Femoral Fractures. 682-694. In: MJ Bojrab (Ed): Current Techniques of Small Animal Surgery. Lea\&Febiger. Philadelphia.

5. Milton, ML (1990) Fractures of Femur. 1805-1817. In: D Slatter (Ed): Textbook of Small Animal Surgery. Second Ed. WB Saunders Comp. Philadelphia.
6. Olmstead ML, Newton CD (1990) Management of Specific Fractures and Traumatic Luxations. 587-604 In: CE Harvey, CD Newton, A Schwartz. (Ed): Sinall Animal Surgcry. JB Lippincott Comp. Philadelphia.

\author{
Yazışma Adresi \\ Dr Ümit Kaya \\ A ÜVeteriner Fakültesi \\ Orlopedi ve Travmatoloji Bilim Dalı \\ O6IIO Diskapl/Ankara
}

